\title{
ANÁLISE DO COMPORTAMENTO DO PADRÃO SAZONAL DO PREÇO DA SOJA EM GRÃO NO PERÍODO DE 1997 A 2010
}

\author{
ANALYSIS OF SEASONAL PATTERN BEHAVIOR OF SOY BEAN \\ PRICE IN PERIOD FROM 1988 TO 2010
}

\author{
Marcelo Brutti Righi ${ }^{1}$, Guilherme Schlender ${ }^{2}$ e Paulo Sérgio Ceretta ${ }^{3}$
}

Recebido em: 14/03/2011 Aprovado em: 27/01/2012

\section{RESUMO}

A soja, ao consolidar-se como a principal e mais expressiva commoditie de exportação do Brasil, apresentou mudanças substanciais em sua cadeia produtiva, sobretudo na administração da sazonalidade dos preços, em que fatores como volume de exportação, nível de oferta e de demanda e custos de produção foram revistos. Com isso, o presente trabalho tem como objetivo analisar o padrão sazonal dos preços negociados no mercado spot da soja em grão a fim de verificar possíveis alterações desses fatores, além de comparar com a composição dos períodos antecedentes. A amostra, dispondo de cotações mensais, compreende o período de 1997 a 2010 , totalizando 161 observações. Os resultados obtiveram índices sazonais acima do valor padrão no período correspondente à colheita dos principais países produtores e exportadores, e índices abaixo do valor no período de entressafra desses pais. Em consequência, o Brasil altera sua atuação no cenário internacional, passando de tomador para formador de preço, assim como modifica sua cadeia produtiva, com revisões de estratégias e de custos produtivos e logísticos.

Palavras-chave: Soja; Cadeia produtiva; Sazonalidade.

\begin{abstract}
Soybeans, to consolidate itself as the main and most significant export commodity in Brazil, showed substantial changes in its production chain, especially in the administration of the seasonality of prices, factors such as export volume, level of supply and demand and costs production had to be revised. Thus, this study aims to examine the seasonal pattern of prices traded in the spot market of soybeans in order to assess possible changes in those factors and to compare the composition of the preceding seasons. The sample, which consists of monthly prices, covers the period from 1997 to 2010, totaling 161 observations. The results indicate rates higher than the seasonal pattern in the corresponding period of harvesting of the main producing and exporting countries, and rates below the value in the period between harvests of these parents. As a result, Brazil changes its role in the international arena, from maker to maker price, as well as modify its production chain, with reviews of strategies and costs of production and logistics.
\end{abstract}

Keywords: Soybean; Production chain; Seasonality.

\footnotetext{
Mestrando em Administração - UFSM, marcelobrutti@hotmail.com ${ }^{2}$ Graduado em Administração - UFSM, sergio.schlender1@gmail.com

${ }^{3}$ Doutor em Engenharia de Produção - UFSM, ceretta10@gmail.com
} 


\section{Introdução}

Nas últimas décadas, a soja consolidou-se como a principal e a mais expressiva commoditie de exportação do Brasil. Considerando todo o complexo - grão, farelo e óleo-, 39 milhões de toneladas foram exportados no referido ano, o que corresponde a $26 \%$ do total das exportações do agro negócio. Isoladamente, a soja em grão representou $62 \%$ da quantidade exportada, contribuindo com mais de 24 milhões de toneladas. Ou seja, $41 \%$ da produção nacional de soja em grão foram comercializadas no mercado externo. Só em 2008, a safra da soja em grão atingiu 60 milhões de toneladas (CONAB, 2009). Concomitantemente, o mercado da soja, canalizado com as operações na Bolsa de Mercadorias e Futuros do Brasil (BMF\&Bovespa), tem direta influência na estrutura econômica do país. Além disso, tal mercadoria ocupa um papel destacado no cenário mundial, já que o Brasil é atualmente o segundo maior produtor da commoditie no mundo, seguido por Argentina, China e Índia, sendo os Estados Unidos o maior produtor (FAO, 2009; BECERRA, 2007).

Contudo, a possibilidade de ganho no mercado da soja ainda não é plenamente aprovei $\neg$ tada por grande parte dos agentes econômicos envolvidos no mesmo. Isso devido à imperfeita compreensão acerca da natureza das flutuações dos preços que, se não podem ser evitadas, ao menos deveriam ser mais bem compreendidas a fim de otimizar suas decisões de proteção e especulação (LAMOUNIER, 2007).

Diante do contexto da soja no Brasil, não se pretende negligenciar os desafios impostos pela cadeia produtiva dessa commoditie. Assim, são ressaltadas questões relacionadas à administração da sazonalidade do preço do produto, em que fatores como oferta e demanda da soja, além do volume de exportações, são cruciais no planejamento dos operadores do mercado que almejam reduzir custos e aumentar a competitividade (OJIMA, 2006).

Associando esse ponto com a mensuração quantitativa, cabe ressaltar que análise de uma série temporal modela o fenômeno estudado para, a partir daí, descrever o seu comportamento. Mais especificamente, a análise de séries temporais financeiras está preocupada com a teoria e prática dos valores de ativos no decorrer do tempo. Destaca-se, nesse contexto, a sazonalidade, que é componente vital de uma série de preços, especialmente se tratando de commodities, os quais são afetados por fatores como entressafra, clima e custos de produção. Dessa forma, o padrão sazonal evidencia quanto, percentualmente, em média, os valores (nesse caso, os preços da soja em grão), em cada mês de uma variável, superam ou ficam abaixo de seu valor médio.

Dando seguimento a essa temática, este trabalho tem como problema de pesquisa identificar a existência do padrão sazonal no preço da soja em grão, no período de 1997 a 2010. Para responder a essa questão, são utilizadas 161 cotações mensais com a finalidade de constatar possíveis alterações na com $\urcorner$ po $\urcorner$ sição das exportações, da oferta e de demanda, e da cadeia produtiva, além de comparar com a composição dos períodos antecedentes.

As seções do presente trabalho estão divididas da seguinte forma: seção 2 , revisão de literatura, que apresentará brevemente aspectos gerais da soja no Brasil, de sua respectiva cadeia produtiva e mercado; seção 3, aspectos metodológicos, que apresentará o delineamento dos dados, o modelo adotado e os procedimentos para o tratamento dos dados; seção 4, análise dos resultados, que evidenciará os resultados decorrentes da aplicação metodológica no objeto de estudo; seção 5 , conclusão, que explanará considerações finais sobre o trabalho. 


\section{Referencial teórico}

A cultura da soja, no Brasil, ocupa posição de destaque no agronegócio, que, por sua vez, tem papel de extrema importância no cenário mundial. Em 2008, considerando desde a produção primária até a indústria de processamento, insumos e serviços, o PIB do agronegócio brasileiro atingiu $\mathrm{R} \$ 710,9$ bilhões, o que corresponde a $26,2 \%$ do PIB nacional, segundo a Confederação Nacional da Agricultura e Pecuária e do Centro de Estudos Avançados em Economia Aplicada da Universidade de São Paulo (CNA/CEPEA-USP, 2009). Nesse mesmo ano, a soja foi responsável por $35 \%$ da balança comercial brasileira de exportações, atingindo 39 milhões de toneladas exportadas no referido ano, o que corresponde a $26 \%$ do total das exportações do agro negócio. Isoladamente, a soja em grão representou $62 \%$ da quantidade exportada, contribuindo com mais de 24 milhões de toneladas. Ou seja, $41 \%$ da produção nacional de soja em grão foram comercializadas no mercado externo (CONAB, 2009).

A chegada da soja em território brasileiro ocorreu em 1882, quando professores da Escola de Agronomia da Bahia realizaram os primeiros estudos de avaliação da cultura de produção que era utilizada pelos americanos. Nove anos após esses estudos, vários testes de culturas semelhantes aos conduzidos pelos professores baianos foram realizados no Instituto Agronômico de Campinas, no estado de São Paulo. Nessa época, a soja era mais utilizada como forrageira do que como planta fornecedora de grãos para a indústria de farelos e óleos vegetais, pois ainda pouco se utilizava da soja para consumo de animais. O principal fator para o sucesso da cultura da soja no país se deve a semelhança do ecossistema do sul do Brasil com o que é predominante no extremo sul dos Estados Unidos, o que favoreceu o êxito na transferência das variedades do grão, bem como as implementações tecnológicas de armazenamento e produção.

Ao passo em que a soja é vista como negócio no Brasil, observa-se o surgimento de um sistema cooperativista dinâmico e eficiente no país, apoiando fortemente a produção, a industrialização e a comercialização das safras, que gera o estabelecimento de uma bem articulada rede de pesquisa de soja, envolvendo governo e iniciativa privada. Além desses fatores citados, pode-se ainda destacar melhorias nos sistemas viário, portuário e de comunicações, facilitando o transporte e as exportações (MELO FILHO e RICHETT, 2008).

Com isso, é perceptível a força da cadeia produtiva da soja no Brasil. Mais do que isso, dá a ela uma profunda organização: seja pela sua importância econômica, seja pelas alterações sofridas nos mecanismos de coordenação de cadeia ao decorrer dos anos. Vale ressaltar que as principais mudanças ocorreram, em especial, no fluxo de insumos, de produtos e de capitais, em que, visando ganhos de competitividade, tiveram que se reestruturar (IICA, 2007).

Fatos importantes ocorreram na reestruturação da cadeia, sobretudo no que tange às transações, tais como: o deslocamento da produção rumo aos Cerrados, o desenvolvimento de novos corredores de exportação, as ineficiências estruturais na indústria processadora e o consequente processo de concentração de fusões e aquisições de empresas (LAZZARINI e NUNES, 1998). Em decorrência disso, as transações entre os principais agentes independentes envolvidos, regidas tanto por um sistema de preços, quanto por contratos, apresentaram uma influência muito mais significativa de elementos, como as exportações, a oferta e a demanda, a volatilidade dos preços da Bolsa de Chicago e a taxa de câmbio (ZYLBERSZTAJN et al., 1998).

A soja é hoje o principal produto do agronegócio brasileiro. Os principais locais de destino das exportações são a 
Europa e a China. A crescente demanda pela soja nos tradicionais países e regiões importadores, como União Europeia, Japão, Coréia e China, está levando a uma forte expansão no mercado global do grão e de seus subprodutos. A América do Sul, particularmente o Brasil e a Argentina, está se tornando a grande área de expansão da produção. As previsões apontam que, nos próximos anos, a contar de 2009, o Brasil deverá consolidar sua posição de maior exportador mundial de soja (FAO, 2009).

No Brasil, em especial, a receita advinda da exportação dos produtos do "complexo soja" cresceu a uma taxa expressiva de 9,4\% ao ano, entre 1993 a 2005. Esse crescimento teve, além de outros fatores preponderantes, a legislação tributária no Brasil como principal elemento impulsionador, ao modificar o padrão comercial, que mudou a oferta de produtos do complexo (do farelo para o grão) nas exportações. Sendo assim, a não ser que ocorra alguma modificação consistente na legislação tributária nacional, a soja continuará ganhando espaço na pauta de exportações, em detrimento da competitividade da indústria esmagadora, que vem sendo gradualmente reduzida (IICA, 2007).

Não obstante, o alongamento das vendas externas de soja deixa o mercado brasileiro mais dependente do comportamento dos preços internacionais e das relações de oferta e de demanda nos principais países consumidores e exportadores do produto. Portanto, à medida que o Brasil aumenta sua necessidade de exportar soja, passa a enfrentar maior concorrência, por exemplo, de grandes polos de exportação como Argentina e Estados Unidos (IICA, 2007).

O mercado da soja brasileiro é balizado pela volatilidade dos preços internacionais das commodities na Bolsa de Chicago. Tal volatilidade é derivada de diversos fatores que fazem os preços oscilarem tanto positiva, quanto negativamente, como as quebras de safras, as necessidades e exigências da demanda dos países consumidores, além da demanda do setor alimentício animal, já que a soja é também matéria-prima na avicultura e pecuária (MISSÃO, 2006). Baseados na citada influência, produtores são obrigados a reverem suas estratégias de comercialização e retenção da soja a um período específico, uma vez que se veem na necessidade de verificar os contextos dos principais países compradores e exportadores. Portanto, encontra-se em curso, no mercado da soja brasileira, uma profunda alteração na relação entre oferta e demanda doméstica, resultante do contínuo crescimento da produção. À medida que a produção brasileira cresce, altera-se o perfil da comercialização doméstica e da exportação, e, com ela, o perfil do mercado financeiro balizado (IICA, 2007).

A Bolsa de Mercadorias e Futuros de São Paulo (BM\&F) é a principal organização onde se realizam os negócios agropecuários no país. Entre estes, estão os relativos ao mercado da soja. Desta forma, a BM\&F se consolida como o principal meio para as transações de compra e venda deste tipo de mercadorias. Além disso, a consolidação de preços para serem negociados e a proteção e gestão dos agentes envolvidos (hedge) são suas funções primordiais (BECERRA, 2007). Não obstante, a BM\&F apresenta mercados específicos, de acordo com a natureza da negociação da mercadoria ou ativo. Entre eles, está o mercado disponível (ou spot), que abrange alguns ativos ou commodities no curtíssimo prazo, normalmente em poucos dias, além de aumentar a flexibilidade das transações, permitindo quaisquer ajustes nos contratos entre demanda e oferta (BECERRA, 2007; CASTRO e LEITE, 2010). Essa influência de oferta e de demanda também fez com que os preços domésticos da soja tivessem forte correlação com as cotações na Bolsa de Chicago, que deu ao produtor a obtenção de um "preço justo" à soja, assim como com a consequente taxa de câmbio, que funcio- 
na tal um seguro contra a inflação e altas dos custos de produção (IICA, 2007).

Outro fator que influencia no comportamento do mercado da soja é o basis doméstico dos preços. Em um produto no qual o preço da oferta é estabelecido com base no preço da demanda final e de custos atrelados ao longo da cadeira produtiva, como é o caso da soja, o comportamento do seu respectivo mercado doméstico correlaciona-se também a fatores que ocorrem desde a produção até ao embarque para exportação (TORRES FILHO, 2004).

\section{Aspectos metodológicos}

Nessa seção, são apresentados os procedimentos metodológicos pertinentes ao cumprimento do objetivo estabelecido para o presente trabalho. Para melhor compreensão, essa seção é divida em três itens: i) delineamento, que aborda a característica dos dados coletados e o tipo de pesquisa efetuada; ii) sazonalidade e séries temporais, que brevemente expõe conceitos e procedimentos para o tratamento dos componentes de uma série temporal; iii) procedimentos empíricos, que descreverá a aplicação para identificar e analisar dos componentes da série temporal formada pelos dados coletados.

\subsection{Delineamento}

Com o objetivo de realizar o presente estudo, efetua-se uma pesquisa descritiva. Nesse sentido, Vieira (2002) destaca que a pesquisa descritiva expõe as características de determinada população ou de determinados fenômenos, sem ter, necessariamente, o compromisso de explicar os fenômenos que descreve, embora sirva de base para tal explicação. Já para Gil (2002), as pesquisas descritivas têm como objetivo primordial a descrição das características de determinada população ou de determinado fenômeno ou, ainda, do estabelecimento de relações entre as variáveis.
A fim de identificar o padrão sazonal do preço da soja no mercado brasileiro, foram coletados dados mensais referentes a esta série histórica composta pelos preços do indicador CEPEA/ ESALQ/BM\&FBovespa correspondentes ao período de janeiro de 1997 a maio de 2010, totalizando 161 observações. A cotação desses dados está em moeda brasileira, isto é, em reais, devido ao fato de que com o uso do real, tem-se uma percepção do contexto nacional do preço desta commoditie.

\subsection{Sazonalidade e Séries Temporais}

Entende-se por série temporal ou histórica, segundo Souza (1989) e Larrote e Cardoso (2001), a classe de fenômenos cujo processo observacional e consequente quantificação numérica geram uma sequência de dados obtidos em intervalos regulares de tempo, durante um período específico. A análise de uma série temporal modela o fenômeno estudado para, a partir daí: descrever o comportamento (sistemático e com um padrão persistente) da série; fazer estimativas e, por último; avaliar quais os fatores que influenciaram o comportamento da série (LARROTE e CARDOSO, 2001; PINDYCK e RUBENFIELD, 2004).

No que tange às séries históricas de preços, tem-se que a análise do comportamento destas apresenta papel fundamental dentro da economia, ao passo que todas as fases das relações econômicas estão diretamente relacionadas aos preços (LAMOUNIER, 2007). Destaca-se, nesse contexto, a sazonalidade, que é componente vital de uma série de preços, especialmente se tratando de commodities, que são atingidos por fatores como entressafra, clima e custos de produção. Assim, o padrão sazonal evidencia quanto, percentualmente, em média, os valores (nesse caso, os preços da soja em grão), em cada mês de uma variável, superam ou ficam abaixo de seu valor médio. 
Dessa forma, a sazonalidade é um desses comportamentos que tem papel destacado em estudos econômicos, juntamente com outros componentes, como o ciclo e como a tendência. Conforme a Abordagem Estrutural de Harvey $(1981,1989)$, tais componentes são assim definidos: i) tendência, que reflete o declínio, a elevação ou a estabilidade (não havendo tendência) do valor médio da série temporal em longo prazo (com observações de até 25 anos); ii) ciclos, referentes à movimentos de elevação e de queda em torno do nível médio de tendência e refletem também o longo prazo; iii) sazonalidade, que, assim como os ciclos, relaciona-se a movimentos para cima e para baixo, em torno de um valor médio, porém reflete períodos menores de tempo, geralmente mensais ou trimestrais, num comprimento constante de 12 meses; iv) componente aleatório, ou componente irregular, que conforme explicado por Pino et al. (1994), refere-se às flutuações não-cíclicas na série temporal .

Diante disso, estudos como os de Morettin e Toloi (1987) e Corrêa e Corrêa (2006), assim como trabalhos realizados por Pino et al. (1994) e Sabes e Alves (2009), definem que uma série temporal pode ser compreendida com base em seus componentes por:

$$
Z_{t}=T_{t} x S_{t} x C_{t} x A_{t}
$$

$Z_{t}=T_{t}+S_{t}+C_{t}+A_{t}$

Representando uma relação aditiva ou multiplicativa dos componentes, em que Zt representa a série temporal, Tt representa a tendência dessa série, $\mathrm{St}$ o componente sazonal, $\mathrm{Ct}$ a variação cíclica e At o componente aleatório.

Não obstante, trabalhos antecedentes já pesquisaram a respeito do padrão sazonal em séries históricas, mais especificamente o da commoditie soja: como os de Arruda et al. (1985) e de Barbosa et al. (2000), nos quais tiveram êxito ao analisar o comportamento do preço negociados, gerando as seguintes constatações:

i) No período de 1979 a 1997 , foi constatado que as exportações brasileiras apresentaram maior volume no primeiro semestre, em especial no que tange à exportação de grão e farelo, com maior intensidade no período simultâneo, ou imediatamente subsequente de entressafra no Hemisfério Norte, o que configura o Brasil mais como um tomador de preço do que formador no mercado internacional de soja e derivados; ii) Quanto ao óleo e derivados, não foi constatado a existência de sazonalidade, devido a possibilidade de substituição entre os diversos óleos vegetais no mercado internacional, além do suprimento exclusivo à demanda interna.

Por fim, ressalta-se a necessidade de uma correta caracterização das propriedades dessas séries que, além de estimar de forma mais eficiente os parâmetros do modelo sob um conjunto de restrições, alcança também considerações de interesse prático, tais como: eficácia de políticas anticíclicas em face de políticas de crescimento, bem como a identificação e a distinção da importância relativa dos impactos das políticas econômicas relacionadas com os movimentos da demanda em relação aos choques de oferta (CASTELAR et al., 2008).

\subsection{Procedimentos Empíricos}

Inicialmente, será verificada a estacionariedade da série do preço de negociação da soja em grão. Para tanto, será aplicado o teste Dickey-Fuller Aumentado (ADF), proposto por Dickey e Fuller (1981), tanto nas séries em nível, quanto em primeira diferença. O teste $\mathrm{ADF}$ está representado pela formulação [3].

$$
\Delta P_{\tau}=\gamma P_{\tau-1}+\sum_{i=1}^{n} \delta_{i} \Delta P_{\tau-i}+\varepsilon_{\tau} .
$$


$\mathrm{Na}$ formulação [3], $\Delta P_{\tau}$ é a variação do preço da soja em grão no instante t; $P_{t-1}$ é o preço da soja em grão no dia de negociação anterior; $\gamma$ e $\varepsilon$ são constantes; e $\varepsilon_{t}$ é uma série ruído branco. Se a hipótese nula não puder ser rejeitada, a série de preços $\left\{P_{t}\right\}$ conterá uma raiz unitária, apresentando não-estacionariedade. As equações são estimadas por Mínimos Quadrados Ordinários (MQO); os valores dos parâmetros obtidos são comparados aos valores críticos das tabelas geradas pelo teste Dickey-Fuller (Dickey\&Fuller, 1981), com base em simulações de Monte Carlo $\mathrm{e}$, mais recentemente, por Mackinnon (1991).

Conforme exposto no referencial teórico, uma série temporal possui fator de tendência. A fim de averiguar o impacto da sazonalidade, é preciso, anteriormente, identificar tanto a presença, quanto o efeito do componente de tendência (MORETTIN e TOLOI, 1987). Nesse sentido, Corrêa e Corrêa (2006) indicam que deve ser traçada uma reta de regressão através dos dados da amostra, com os coeficientes estimados via mínimos quadrados ordinários (OLS). Essa reta, que de certa forma reflete o componente de tendência da série temporal, pode ser expressa matematicamente na formulação [4]:

$\mathrm{S}_{\mathrm{t}}=\beta_{0}+\beta_{1} \mathrm{t}+\varepsilon_{\mathrm{t}}$

$\mathrm{Na}$ qual, $S_{\tau}$ epresenta preço da soja no período $t ; \beta_{0}$ representa o intercepto da reta de regressão; $\beta_{1}$ indica o impacto temporal, isto é, o componente de tendência, representando, assim, a inclinação da reta; $\varepsilon_{t}$ é o erro de estimativa da reta de regressão.

Após a identificação da reta que representa a tendência, faz sentido analisar o componente de sazonalidade. A forma de realizar tal procedimento é, conforme Corrêa e Corrêa (2006), calcular quanto, percentualmente em média, os valores de cada mês do preço da soja em grão superaram ou estiveram abaixo da reta de tendência. Tais percentuais são os índices sazonais, representados por [5].

$I S_{i}=\frac{\mathbf{1}}{n} \sum_{i=\mathbf{1}}^{n} \frac{S_{i, t}^{*}}{\overline{S^{*}}}$.

Em [5], $I S_{i}$ é o índice sazonal do mês $i ; S_{i, t}^{*}=S_{i, t}-\beta_{\mathbf{1}} t$ é o preço da soja em grão do mês $i$ sem o componente de tendência, previamente retirado; $n$ é o número de observações do preço da soja para o mês $i$; $S^{*}$ é a média global do preço da soja em grão.

\section{Análise dos resultados}

Inicialmente, foi realizado teste ADF para averiguar a estacionariedade da série composta pelos preços da soja em grão. Os resultados desse teste, para o preço da soja em nível e em primeira diferença, são expostos na Tabela 1. Dessa forma, verificou-se estacionariedade apenas para série em primeira diferença. Tal identificação não traz alteração para o escopo principal do presente artigo, uma vez que os componentes de tendência e sazonalidade são determinísticos, e não estocásticos, sem comprometer a identificação proposta no objetivo principal.

Tabela 1 - Teste ADF do preço da soja em nível e primeira diferença.

\begin{tabular}{lcc}
\hline Variável & Teste ADF & p-valor \\
\hline Nível & -1.416 & 0.576 \\
Diferença & $\mathbf{- 2 7 . 9 5 9}$ & 0.000 \\
\hline * Valores em negrito são significativos ao nível de 5\%.
\end{tabular}

No que segue, são expostas: a Figura 1, que representa cada componente da série histórica da soja no período de 1997 a 2010, e a Figura 2, que evidencia em formato gráfico os índices sazonais da soja, para posterior análise.

Na Figura 1, é apresentada a decomposição em cada item necessário para a análise do padrão sazonal da soja no período amostral, sendo tais categorias: a tendência, a sazonalidade e o componen- 
te aleatório (restante). Frisa-se a identificação da presença de tendência antes da análise da sazonalidade, sendo positiva e com valores (preços) cada vez maiores ao passar do tempo. Quanto ao componente aleatório, sua presença é visível, porém não é o objeto-estudo em questão.

Conforme apresentado na Figura 2, os índices sazonais de preços referentes à soja em grão comercializada na BM\&F situados acima da média, representada pelo valor 1.00 , ocorreram entre Outubro e Fevereiro, período onde ocorre a colheita dos principais produtores mundiais de soja (EUA, Brasil, Argentina e China). Esse resultado, comparado com outros períodos antecedentes, conforme os estudos realizados por Arruda et al. (1985) e de Barbosa et al. (2000), apresenta um comportamento oposto.

Além disso, o período em que os índices sazonais estão abaixo da média é correspondente aos meses de entressafra dos principais países produtores.

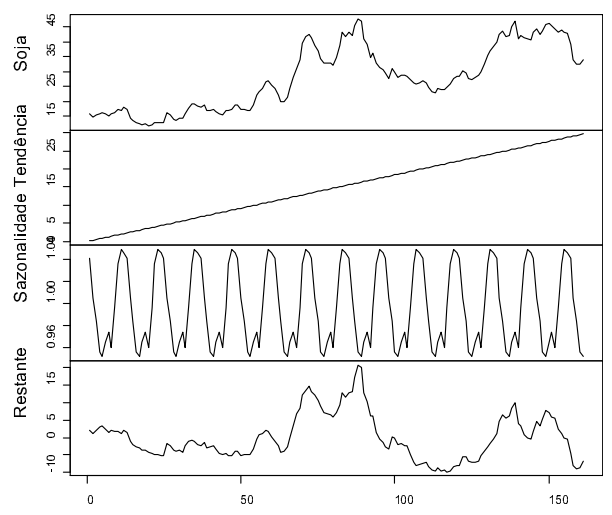

Figura 1 - Decomposição da série temporal da soja no período de 1997 a 2010.

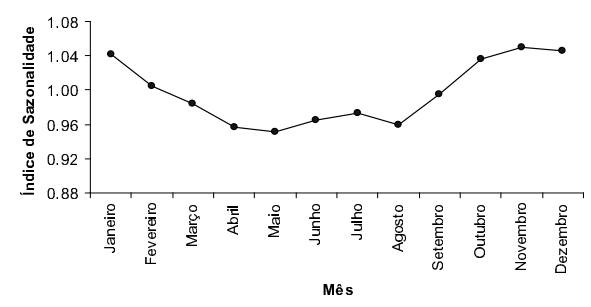

Figura 2 - Gráfico dos índices sazonais mensais do preço de $60 \mathrm{Kg}$ de soja em grão negociados na BM\&F.
Vale também ressaltar que a variação entre o ponto máximo e o ponto mínimo nos índices é relativamente baixa, isso indica que o preço da soja no Brasil apresenta pouca oscilação mensal ao longo do ano. Tal constância levanta a possibilidade de o preço balizador internacional não mais possuir tanta influência no preço doméstico da soja, como ocorria no passado. Dessa forma, esses resultados são contrários ao que foi apresentado por Pino e Rocha (1994) e Barbosa et al. (2000), no qual argumentavam sobre a participação do Brasil como tomador de preço no mercado internacional.

A referida mudança pode ser advinda de fatores como: i) a possibilidade de que os preços domésticos atualmente estejam menos sucumbidos à influência de um balizador mundial, no caso, a Bolsa de Chicago; ii) uma possível influência de políticas de proteção que favorecem a venda de produtos fora do período de safra dos grandes exportadores, mais especificamente, a taxa de câmbio envolvida na negociação (MARGARIDO e SOUZA, 1998; IICA, 2007).

Com isso, a forte participação do Brasil no mercado internacional e a provável mudança na oferta e na demanda global fizeram com que ocorressem revisões em outro ponto importante na sazonalidade dos preços da soja: o custo de produção envolvido na cadeia produtiva. Como resultado, agentes envolvidos na cadeia, sob a necessidade de reverem suas estratégias, melhoraram a competitividade do país nesse setor. Dessa forma, detalhes como a retenção do produto para períodos entressafra e os custos de logística e armazenamento dos produtos começaram a ser observados e repensados (OJIMA, 2006).

\section{Considerações finais}

O presente estudo teve como objetivo analisar o padrão sazonal dos preços 
negociados no mercado spot da soja em grão, a fim de constatar possíveis alterações na composição das exportações, da respectiva oferta e demanda, além de fatores atrelados à cadeia produtiva. Para isso, foi analisado o comportamento do preço no período correspondente a janeiro de 1997 a maio de 2010, totalizando 161 observações. Nessa série de preços, procurou-se identificar o componente sazonal intrínseco ao mercado analisado. Esse tipo de identificação foi estudada para outros mercados, tais como: café (LAMOUNIER, 2007); trigo (SILVA FERREIRA e NOGUEIRA JUNIOR, 2004); amendoim (SABES e ALVES, 2009); ovinocultura (VIANA e SOUZA, 2007); uva fina (SATO, MARTINS e BUENO, 2004); setor agrícola (CASTELAR et al., 2008) entre outros.

Ao analisar os dados resultantes dessa identificação, constatou-se que os índices sazonais apresentaram valores acima de 1.00 (valor padrão) num período que corresponde aos meses de colheita nos principais países produtores e exportadores da commoditie (outubro a fevereiro). Também se evidenciou que os índices sazonais abaixo do valor padrão foram encontrados em períodos de entressafra nesses países (março a setembro). Esse comportamento é diverso, por exemplo, de mercados como o café e como o amendoim, este, em período de safra, apresenta índices sazonais negativos, atrelado a um aumento da oferta com a demanda constante (LAMOUNIER, 2007; SABES e ALVES, 2009). No caso do trigo, corrobora-se com o comportamento apresentado pela soja, em que o índice sazonal do trigo americano, principal produtor e exportador mundial, apresenta-se positivo nos períodos de safra e negativo nos períodos entressafra (SILVA FERREIRA e NOGUEIRA JUNIOR, 2004).

Essas constatações demonstram que os principais produtores e exportadores apresentam influência determinante na sazonalidade dos preços. Isso se deve, sobremaneira, a fatores como: à menor sobrepujança da Bolsa de Chicago nos preços domésticos, atuando como um balizador dos preços a nível mundial; à consequente possibilidade de políticas de proteção que dificultam a venda do produto além do período de safra dos grandes exportadores.

Também, ao ser analisada mais especificamente a atuação do Brasil, percebe-se a alteração significativa em sua participação no cenário aqui descrito, de tomador para formador de preço do produto, possivelmente ao volume de produção e de exportações e outros atrativos de investimentos na cadeia produtiva da soja em grão. Além disso, ressaltam-se as reestruturações ocorridas nessa cadeia, que afetaram a estrutura e os agentes envolvidos na mesma: custos de produção e logísticos, assim como a retenção do produto para outros períodos, tiveram que ser analisados (OJIMA, 2006).

Porém, o trabalho em questão apresenta como limitações o tamanho amostral dos dados, que restringiu a possibilidade de uma maior consistência no calculo dos índices sazonais. Sugerem-se possíveis estudos envolvendo a sazonalidade dos outros componentes do "complexo soja" (farelo, óleo e derivados) e de seus agentes (produtor, atacado, exportador), assim como de outras commodities, a fim de dar melhor compreensão a respeito da natureza das flutuações de preços, aperfeiçoando as decisões e as estratégias dos agentes econômicos envolvidos.

\section{Referências bibliográficas}

ARRUDA, M. de L. do C.; CARVALHO, F.C.; NOGUEIRA JUNIOR, S. Processamento, estocagem e exportação de soja em grão e derivados e sua relação com a alternância das safras estadunidense e brasileira. IEA - Instituo de Economia Agrícola, Relatório de pesquisa. São Paulo, SP: Instituto de Economia Agricola. Abr., 1985. ISSN 0101-5109 
BARBOSA, M. Z. FERREIRA, C. R. R. P. T. FREITAS, S. M. Comportamento dos preços de soja e derivados nas exportações brasileiras no período 1988-97. Informações Econômicas. São Paulo: IEA - Instituo de Economia Agrícola. Fev., 2000. ISSN 1678-832X

BECERRA, K. Mercado de Capitais: Bolsa de Mercadorias e Futuros do Brasil. Universidade Federal do Rio de Janeiro. Rio de Janeiro, Maio de 2007. Disponível em: <http://artigocientifico.tebas.kinghost.net/uploads/ artc_1199900017_64.pdf $>$. Acesso em: $02 / \overline{03} / 2011$.

CASTELAR, I.; OLIVEIRA JUNIOR, J.N.; TROMPIERI NETO, N.; FERREIRA, R. T. Setor agrícola brasileiro: uma aplicação do modelo de tendências e ciclos comuns no período de 1990 a 2005. Economia, vol. $9, \mathrm{n}^{\mathrm{o}} 2$, pp. 385-409. 2008. ISSN 1517-7580.

CASTRO, N. J.; LEITE, A. L. S. Preço spot de eletricidade: teoria e evidências do caso brasileiro. In: IV Encontro de Economia Catarinense, 2010, Criciúma. IV Encontro de Economia Catarinense, ANPEC -Associação Nacional dos Centros de Pós-Graduação em Economia, 2010.

CNA/CEPEA-USP. Confederação Nacional da Agricultura e Pecuária - Centro de Estudos Avançados em Economia Aplicada, Universidade de São Paulo. PIB do Agronegócio. Disponível em: $<$ http://www.cepea.esalq.usp.br/pib/>. Acesso em: abr. 2010.

CONAB. Companhia Nacional de Abastecimento. Indicadores da Agropecuária. Ano XVIII, n. 03, mar. 2009. Disponível em: <http://www.conab. gov.br/conabweb/IA-mar09.pdf>. Acesso em: 29 abr. 2010.

CORRÊA, C. A.; CORRÊA, H. L. Administração de produção e operações: Manufatura e serviços - Uma aborda- gem estratégica. 2 ed. São Paulo, SP: Editora Atlas, 2006.

FAO. Food and Agricultural Organization of the United Nations. Major Food and Agricultural Commodities and Producers. In: Statistical databases. Disponível em: $<\mathrm{http}: / / \mathrm{www}$. fao.org/es/ess/top/commodity.html?lan $\mathrm{g}=\mathrm{en} \& \mathrm{item}=236 \& \mathrm{year}=2005>$. Acesso em: 02/03/2011.

HARVEY, A. Forecasting, structural time series models, and the Kalman filter. 1. ed. Cambridge: Cambridge Univesity Press, 1989. 554 p.

HARVEY, A. Time series models. 1. ed. New York: John Wiley \& Sons Inc, 1981. $230 \mathrm{p}$.

IICA, Instituto Interamericano de Cooperação para a Agricultura. Cadeia produtiva da soja. Séries Agronegócios. Vol. 2. 2007. Disponível em: http:// www.iica.org.br/Docs/ CadeiasProdutivas/Cadeia $\% 20$ Produtiva $\% 20 \mathrm{da} \% 20$ Soja.pdf. Acesso em: 02/03/2011.

LAMOUNIER, W. M. Tendência, ciclos e sazonalidade nos preços spot do café brasileiro na NYBOT. Gestão e Produção, vol.14, no.1, p.13-23. Abr, 2007. ISSN 0104-530X

LAZZARINI, S. G.; NUNES, R. Competitividade do sistema agroindustrial da soja. In: FARINA, E. M. M. Q. Competitividade da agroindústria brasileira. Pensa-Ipea, CD-ROM, 1998.

MARGARIDO, M. A.; SOUZA, E. L. L. Formação de preços da soja no Brasil. Agricultura em São Wesley Vieira da Silva, Elinaldo Leal Santo e Luciana Santos Costa V. da Silva Caderno de Pesquisas em Administração, São Paulo, v. 10, no 3, p. 69-78, julho/setembro 200378 Paulo, São Paulo: Departamento da Produção Vegetal, v. 45, n. 2, p. 52-61, 1998. 
MELO FILHO, G. A.; RICHETT A. Perfil socioeconômico e tecnológico dos produtores de soja e milho de Mato Grosso do Sul. In: EMBRAPA/CPAO. Dourados, 2008.

MORETTIN, P. A.; TOLOI, C. M. Séries temporais. 2. ed. São Paulo, SP: Atual Editora, 1987.

OJIMA, A. O. Impactos da sazonalidade na safra de soja. São Paulo: CCTC-IEA, 2006.

PINO, F. A.; FRANCISCO, V. L. F. S.; SUEYOSHI, M. L. S.; AMARAL, A. M. P. Sazonalidade em séries temporais econômicas: um levantamento sobre o estado da arte. Agricultura em São Paulo, SP, vol. 41, n³, pp. 103133, 1994.

SABES, J. J. S.; ALVES, A. F. Análise comparativa dos padrões sazonais de comportamento dos preços do amendoim no período de janeiro de 1996 a dezembro de 2005. Revista em Agronegócios e Meio Ambiente, v.2, n.2, p. 35-62, Mai./Ago., 2009.

SATO, G.S.; MARTIN, V.A.; BUENO, C.R.F. Sazonalidade dos preços de uva fina para mesa no estado de São Paulo. Informações Econômicas, São Paulo, v. 34, n.8, p. 38-40, ago. 2004.

SILVA, J. R.; FERREIRA, C. R. R. P. T.; NOGUEIRA JUNIOR, S. Padrão sazonal de preços do trigo: São Paulo, Paraná, Argentina, Estados Unidos. Informações Econômicas, São Paulo, v.34, n.3, p. 7-14, mar. 2004.

TORRES FILHO, E. T. Petróleo: concorrência, regulação e estratégia. Economia Política Internacional: Análise Estratégica. n. 2 - jul./set. 2004 (21-26). Disponível em: <http://www. eco.unicamp.br/asp-scripts/boletim ceri/boletim/boletim2/04-Ernani.pdf $>$. Acesso em: 02/03/2011.
VIANA, J. G. A.; SOUZA, R. S. Comportamento dos preços dos produtos derivados da ovinocultura no Rio Grande do Sul no período de 1973 a 2005. Ciência e agrotecnologia, Lavras, v. 31, n. 1, p. 191-199, fev. 2007.

VIEIRA, V. A. As tipologias, variações e características da pesquisa de marketing. Revista da FAE, Curitiba, v.5, n.1, p.61-70, jan./abr. 2002.

ZYLBERSZTAJN, D.; LAZZARINI, S. G.; MACHADO FILHO, C. A. P. Pers-pectivas da aplicação da biotecnologia no Sistema Agroindustrial Brasileiro: o exemplo da soja RoundupReady. Programa de estudos dos negócios do sistema agroindustrial. VIII Seminário Internacional Pensa de Agrobusiness, 1998. 